\title{
Cómo analizar las representaciones sociales contenidas en los libros de texto de Historia
}

\author{
Francisco Bernete
}

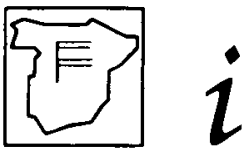

Del mismo modo que cabe contemplar y usar los medios de comunicación como recursos didácticos, también es posible enfocar los más tradicionales instrumentos didácticos desde una perspectiva comunicacional. El libro de texto tiene una dimensión enculturizadora por ser transmisor de información y, como tal, pueder ser también proporcionador de visiones del mundo etnocéntricas y de prejuicios de diversa índole. El artículo muestra la aplicación de una metodología para objetivar la estructura de la representación de los personajes de diferentes nacionalidades en el producto que nos parece más adecuado para ello: el libro de texto de Historia.

\section{EL MANUAL DE HISTORIA EN EL CONTEXTO DE LOS MATERIALES QUE CONTRIBUYEN A LA ENCULTURIZACION DE LOS ESCOLARES}

El libro de texto que, desde un punto de vista pedagógico, es uno de los instrumentos didácticos que se utilizan en el sistema de enseñanza, se aborda en esta ocasión como producto comunicativo y no como instrumento didáctico, teniendo presente, por supuesto, la finalidad pedagógica con la que se elabora dicho producto: los manuales de enseñanza difunden unos conocimientos específicamente elaborados para que sean aprendidos por sus destinatarios.

El manual de Historia, como cualquier otro utilizado en la escuela, debe contemplarse como un producto enculturizador. La definición del término «enculturización» que conviene en este caso, es la siguiente: la enculturización es un proceso, socialmente institucionalizado, de transmisión de información que tiene, entre otras, la finalidad de asegurar la integración de los individuos en un grupo determinado.

Las actividades enculturizadoras están orientadas a mantener las pautas del grupo en el cual se desenvuelven los individuos'. Dichas pautas son transmitidas a los miembros de una comunidad por diferentes vías, entre las cuales se encuentran las instituciones educativas. 
Los libros de texto son enculturizadores porque proveen a los estudiantes de relatos que contienen determinadas representaciones colectivas ${ }^{2}$, o visiones del mundo destinadas a ser compartidas; entre ellas, las referidas a personajes del grupo nacional propio (de cada pais) y las referidas a personajes de grupos nacionales ajenos.

Estas visiones del mundo, representan las interpretaciones de la realidad que las autoridades educativas, aunque sea de manera inconsciente, tienen por apropiadas. El descubrimiento de la estructura subyacente en dicha visión del acontecer sirve para desvelar cómo los narradores median cognitivamente entre los sucesos que pasan y los valores que traen a colación para juzgar tales sucesos.

Los modelos de representación de la realidad que se proponen en los libros de texto suelen tenerse como legitimados y dignos de confianza por parte de los alumnos; de ahí, su capacidad de influencia. En cuanto productor de modelos de representación de la realidad, el libro de texto está comprometido en la evolución social.

Las representaciones propuestas en los relatos son elementos de un Sistema de Comunicación, abierto al Sistema Social de una comunidad y al Sistema Cognitivo de unos sujetos

Las representaciones contenidas en la narración deben ser distinguidas de otras representaciones, de diferente naturaleza, con las cuales están relacionadas: las «representaciones cognitivas» individuales y las «representaciones consolidadas» en una comunidad de personas. La finalidad de esta distinción es configurar el marco en el cual se insertan las primeras (contenidas en la narración) como objeto de estudio.

A) «Las representaciones cognitivas individuales son productos elaborados por la actividad mental de los sujetos. Se crean y se modifican relacionando un conjunto de datos como igualmente correspondientes a una entidad, desde algún punto de vista. Por ejemplo, los datos «baila bien", "huele mal» $y$ «lascivo" pueden ser combinados mentalmente por alguien, como el conjunto correspondiente a la entidad "NEGRO».

B) Las representaciones contenidas en los relatos son interpretaciones (ofrecidas a los destinatarios del relato) de lo que existe o de lo que acontece en el entorno» (Martín Serrano, 1986) Están explícitas en las narraciones de los productos comunicativos como conjunto de rasgos atribuidos a las entidades que son objeto de referencia en la comunicación.

C) "Las representaciones consolidadas en cada cultura son visiones del mundo en las que se legitiman los valores, las peculiaridades históricas, políticas, culturales y materiales de la comunidad (Martín Serrano, 1986).

En la figura 1, se han situado:

(A) Las representaciones que son producto de la actividad mental de los individuos, como elementos pertenecientes a un Sistema Cognitivo.

(B) Las representaciones que están contenidas en los relatos, como elementos incluidos en un Sistema de Comunicación.

(C) Las representaciones consolidadas en una comunidad, como componentes de un Sistema Social.

El Sistema Cognitivo, el Sistema de Comunicación y el Sistema Social se representan con corchetes, para indicar la apertura de cada sistema a posibles afectaciones provenientes de cambios producidos en otros sistemas. A su vez, las flechas indican que son posibles las afectaciones entre sistemas en todas las direcciones. De acuerdo con «El modelo dialéctico de la comunicación» (Martín Serrano, 1981 y 1982), se acepta la concepción de los sistemas como autónomos e interdependientes. En dicho modelo, ningún sistema es considerado como determinante o como depen- 
diente de otro. El carácter abierto de los tres sistemas ha de tenerse en cuenta al analizar los textos, aunque no se estudien las coordenadas espacio-temporales que contextualizan la producción de relatos.

FIGURA 1

Marco en el que se inserta el objeto de estudio

\begin{tabular}{|c|c|c|}
\hline (A) & (B) & 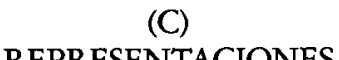 \\
\hline REPRESENTACIONES & REPRESENTACIONES & REPRESENTACIONES \\
\hline CONGNITIVAS & $\begin{array}{l}\text { PROPUESTAS EN } \\
\text { LOS RELATOS }\end{array}$ & CONSOLIDADAS \\
\hline 1 & 1 & 1 \\
\hline $\begin{array}{l}\text { (en la conciencia } \\
\text { de los sujetos) }\end{array}$ & $\begin{array}{l}\text { (en un producto } \\
\text { comunicativo) }\end{array}$ & $\begin{array}{l}\text { (en una comunidad } \\
\text { de personas) }\end{array}$ \\
\hline 1 & 1 & । \\
\hline $\begin{array}{l}\text { Son elementos } \\
\text { de un }\end{array}$ & $\begin{array}{l}\text { Son elementos } \\
\text { de un }\end{array}$ & $\begin{array}{l}\text { Son elementos } \\
\text { de un }\end{array}$ \\
\hline$\left[\begin{array}{c}\text { SISTEMA } \\
\text { COGNITIVO }\end{array}\right]$ & $-\left[\begin{array}{c}\text { SISTEMA DE } \\
\text { COMUNICACION }\end{array}\right]$ & $\rightarrow\left[\begin{array}{c}\text { SISTEMA } \\
\text { SOCIAL }\end{array}\right]$ \\
\hline
\end{tabular}

Conviene insistir en que las influencias entre sistemas son posibles, pero no son seguras: Las representaciones cognitivas, las representaciones ofrecidas en un producto comunicativo y las representaciones consolidadas en una comunidad pueden ser, en algunos casos, coincidentes en contenido. Pero de ahí no puede deducirse que existan relaciones de dependencia entre ellas. En el ejemplo de la entidad "NEGRO», las representaciones cognitivas y las representaciones contenidas en una narración serían coincidentes si los datos ofrecidos en un libro a propósito de los personajes «negros» fuesen los mismos que combinan mentalmente los lectores durante o después de su lectura. Este hecho no indicaría, por sí solo, que las representaciones ofrecidas en el libro hayan sido, necesariamente, las fuentes de las representaciones cognitivas.

De modo semejante, los textos de la enseñanza oficial intervienen en la visión del mundo de los adolescentes junto con otros productos (películas, discos, tebeos, etc.) y agentes (profesores, padres, amigos, etc.). Cada una de esas instancias enculturizadoras puede transmitir representaciones, sean o no prejuiciosas, sobre determinadas razas, clases sociales, etc. y, por supuesto, sobre países o áreas geográficas.

La posible influencia de los libros de Historia se inscribe en el juego de todas esas fuentes alternativas de representaciones. Si el resultado fuese la interiorización, por parte de los sujetos, de actitudes discriminatorias, en favor o en contra de alguno de los grupos representados, se produciría la paradoja de que la comunicación se constituyese en inductora de la incomunicación entre los hombres.

\section{EL LIBRO DE TEXTO DE HISTORIA, COMO POSIBLE FUENTE DE PREJUICIOS NACIONALES}

¿Por qué elegir textos de Historia para analizar representaciones de identidades nacionales?

Las representaciones propuestas en los relatos se contemplan como «visiones del acontecer». El libro de historia proporciona un relato de lo que acontece y de lo 
que aconteció, que supone necesariamente una representación. Por ejemplo, si se estudian las descripciones de los seres humanos y las instituciones que aparecen como personajes del relato, se comprueba lo siguiente: a los sujetos y organizaciones mencionados en la narración se les atribuye una función o papel social (por ejemplo: colonizador, gobernante, independentista), que el personaje desempeña -según el texto- dotado de unas determinadas características, personales y públicas: cualidades, sentimientos, derechos, etc. susceptibles de ser recogidos en un análisis de contenido, como datos que constituyen la representación del personaje.

Las representaciones de diferentes entidades nacionales (objetos, personas, organizaciones, etc.) pueden analizarse en los relatos difundidos en productos comunicativos de distinta naturaleza: periódicos, programas de radio y televisión, vallas publicitarias, folletos de instrucciones, etc., todos aquellos productos donde sea posible hallar atribuciones a lo nacional y a lo no nacional.

Los libros de texto de Historia son particularmente apropiados como productos comunicativos donde cabe encontrar representaciones estereotipadas del «ser nacional» frente al «ser extranjero» porque, en las narraciones que vehiculan, los protagonistas (individuos, colectivos, instituciones, etc.) aparecen mencionados como pertenecientes a una u otra nación. Estos relatos constituyen una fuente importante de representaciones colectivas, que provee de «señas de identidad» al endogrupo nacional ${ }^{3}$.

Diversos antropólogos (Margaret Mead, Ruth Benedict, Eric Erikson, entre ellos) han atribuído la formación del "carácter nacional" a la educación, porque en ella tendrían su origen los sentimientos que unifican a la nación. Y ha sido precisamente la enseñanza de la Historia patria la que más se ha utilizado en la educación pública con el propósito de contribuir a la forja de una nación. Naturalmete, esa «construcción» adquiere una forma diferente, dependiendo, entre otros factores, de la perspectiva adoptada por cada historiador.

En todo caso, el libro de historia (utilizado o no como manual de enseñanza) proporciona:

a) Información sobre los acontecimientos que se suceden en la vida de un grupo (lo «emergente»); y también,

b) Información sobre la «naturaleza» del grupo (lo «inmanente») ${ }^{4}$.

El mantenimiento de la identidades grupales frente a lo cambios históricos

"El bombre no tiene naturaleza; tiene bistoria». (Ortega y Gasset).

"El mito transforma la bistoria en naturaleza".

(Roland Barthes).

Las frases de Ortega y Gasset y de Roland Barthes dan cuenta de una doble condición del hombre: de «ser» que cambia y, al mismo tiempo, de «ser» que está interesado en el mantenimiento de la identidad del grupo al que pertenece.

Las consideraciones sobre la identidad de los pueblos incluyen interrogantes a propósito de:

- la propia existencia de un carácter colectivo,

- la mutabilidad o inmutabilidad del mismo y

- la naturaleza determinante o determinada del carácter de los pueblos con relación a su comportamiento históricos.

La identidad grupal puede ser abordada de dos formas, desde el punto de vista de su mantenimiento histórico:

A) De una forma estática, como un conjunto de rasgos permanentes, que caracterizarían a un mismo grupo en etapas históricas sucesivas; y también 
B) De una forma dinámica, como un proceso histórico y social, que sería el determinante de los elementos que integran la identidad.

Esta segunda perspectiva es compartida, entre otros sociólogos, por A. Perez Argote (1982) y F. Mercade (1986):

«La identidad colectiva nacional o de otro tipo, se presenta en tanto que fenómeno social como algo cambiante, histórico, con posibilidades de incoherencia consigo misma" GARmendia, J. A.; PARra LuNA, F. y PÉreZ, A.(1982):. A bertzales y vascos. p. 14

Si una identidad comporta unos atributos invariables en el tiempo, es muy importante ver que es esta identidad lo que es importante. Los atributos pueden cambiar o ser diferentes y mantenerse paradójicamente «invariables", porque continúan siendo fieles a los mismos principios o porque han cambiado los contextos sociales en los que éstos se producían»

HERNÁNDEZ, F. y MERCADE, F. (1986): Estructuras sociales y cuestión nacional en España. p. 19-20.

En los relatos, podrían cambiar o mantenerse invariables los atributos con los cuales se describe a un mismo colectivo en dos épocas diferentes. G. W. Allport (1971), opina que las representaciones estereotipadas de los grupos en las narraciones se mantienen relativamente invariantes en el transcurso del tiempo. El autor de "La naturaleza del prejuicio» aporta datos, según los cuales el tratamiento dado a los grupos minoritarios en más de 300 libros de texto revela que muchos de ellos perpetúan estereotipos negativos. Allport interpreta tal tratamiento como "debido no a un intento malévolo, sino a tradiciones insertas en la cultura, que los autores de los libros adoptaron sin proponérselo» (Op. cit. pág. 213).

Un análisis diacrónico que se aplicase sobre los textos de un país en una época determinada (por ejemplo, Cuba, antes de la Revolución) y sobre los textos de ese mismo país en una época posterior (Cuba, despúes de la Revolución), nos permitiría comprobar si han variado los datos con los cuales se representa a cada uno de los colectivos (indígenas, españoles, iberoamericanos, etc.).

Otros factores que favorecen la formación de esteretipos nacionales en los manuales de Historia

Además del mencionado carácter de los libros de Historia, como vehículo para transmitir, al mismo tiempo, información sobre los aconteceres y sobre la propia identidad de los protagonistas, según su intervención en la constitución del Estadonación, cabe mencionar otras razones que también contribuyen a que los manuales de Historia sean una importante fuente de estereotipos nacionales. Mencionaremos las tres siguientes:

A. La vicariedad de los textos de Historia,

B. Las tendencias prejuiciosas y etnocéntricas de los aurores; y

C La ambigüedad del concepto «nación»

\section{La vicariedad de los textos de Historia}

La actividad de representación cognitiva, que llevan a cabo los receptores de la comunicación, supone la capacidad de hacerse una imagen de algo que la mayor parte de las veces no tienen presente. Así les ocurre a los lectores de los libros de texto: son receptores de unos datos de los que no saben si son verdaderos o falsos, ni pueden comprobarlo cuando se realiza la comunicación. Es el tipo de comunicación que M. Martín Serrano (1981) denomina «de verificación vicaria», caracterizada porque descansa implícitamente en dos supuestos, que crean un particular modo de relación entre emisor y receptor: ${ }^{6}$

1) El emisor debe confiar en la capacidad de reconstrucción del receptor, es decir, de elaborar una representación adecuada a partir de lo que está expresándose. 
2) El receptor debe aceptar la autoridad del emisor. En este caso, los escolares deben aceptar la capacidad de los autores para comunicar a propósito de algo o alguien, utilizando para ello los datos de referencia pertinentes (Martín Serrano, 1981) ${ }^{7}$.

La verificación de los datos por parte del receptor es imposible en todos los procesos de comunicación vicaria ya que, por definición, el objeto a propósito del cual se comunica no está presente cuando se lleva a cabo la comunicación ni participa en la génesis de los datos. Es decir, el receptor acepta la autoridad del emisor (su capacidad para utilizar datos de referencia que sean pertinentes), sin saber si están todos los datos que cumplen esta cualidad o faltan algunos y sin saber, siquiera, si pertenecen o no al objeto de referencia. Cuando dicho. objeto está constituido por aconteceres que han tenido lugar en el pasado de una comunidad, tampoco ha sido conocido directamente por el emisor. Por lo tanto, hemos de tener presente que el historiador no selecciona los acontecimientos - ni los datos para describirlos- a partir de su experiencia personal, sino de las selecciones previas de otros autores. Generalmente, en los manuales de Historia no suelen estar explícitas ni las fuentes ni las pruebas que justificarían la versión que ofrecen de lo sucedido.

\section{Las tendencias prejuiciosas y etnocéntricas de los autores}

El concepto de «prejuicio» y su relación con «estereotipo».

El concepto de «prejuicio» se usa habitualmente para designar una actitud negativa y, a menudo, despreciativa, respecto de personas identificadas por su profesión, sexo, religión, nacionalidad o cualquier otro criterio que marque la separación entre quienes tienen el prejuicio y quienes son prejuzgados. Así lo define Michael Billig (1984) : «podemos considerar que los prejuicios constituyen opiniones dogmáticas y desfavorables respecto a otros grupos y, por extensión, respecto a miembros individuales de otros grupos».

El prejuicio también puede ser positivo. Max Horkheimer (1972) ha señalado el motivo y lugar donde comienza a entenderse el término en sentido negativo

«Sólo en Inglaterra, donde la experiencia, desde siglos, aparecía como la suprema instancia del conocimiento, la palabra "prejucio», o sea la opinión que precede o quiere sustraerse a la comprobación por medio de los hechos, aparte de la Biblia, se consideró desde hace mucho tiempo como prejucio en el sentido negativo»

MAX HORKHEIMER (1972), p. 179.

Con frecuencia, el juicio positivo a propósito de un grupo determinado implica el negativo acerca de otro grupo distinto, al atribuir al primero rasgos evaluados positivamente, que no se atribuyen al segundo. $Y$ viceversa: el juicio negativo a propósito de un grupo implica el positivo acerca de otro, al adjudicar al primero rasgos evaluados negativamente, que al segundo no se adjudican.

El análisis de los textos de Historia de distintos países, puede poner de manifiesto, los prejuicios nacionales positivos y negativos. $\mathrm{Y}$ ambos, tanto a propósito del grupo nacional que pertenece al mismo país donde se editan los libros, como a propósito de otros grupos nacionales.

El estereotipo cumple, entre otras, una función de racionalización del prejuicio. El estereotipo no es «la» causa del prejuicio -aunque puede alimentarlo- sino una justificación. La representación estereotipada se esgrime como un recurso para la aceptación o el rechazo más o menos discreto de un grupo.

Los estereotipos y prejuicios negativos pueden dar lugar a discriminaciones, es decir, a comportamientos dirigidos contra quienes son objeto del prejuicio. Estas discriminaciones conllevan frecuentemente imágenes simplificadas y desfavorables del grupo discriminado. Así ha ocurrido en U.S.A., respecto a los negros; en ciertas naciones europeas, respecto a los judíos o los emigrantes; en España, respecto a los gitanos o los moros; en América Latina, respecto a las etnias de negros e indígenas: 
«Esas identidades culturales (de negros e indígenas) son cotidianamente utilizadas para descargar sobre ellas el resentimiento nacional, para echarles la culpa del atraso y ejercer sobre ellas un racismo que la retórica populista no alcanza nunca a disfrazar del todo» Martín Barbero, J. (1988). Pág. 39.

El concepto de «etnocentrismo» y su relación con "prejuicio» y «estereotipo».

El etnocentrismo se manifiesta, entre otras formas, como la tendencia a tener una representación más positiva del grupo propio (clase social, nacionalidad, profesión, etc.) que de los grupos ajenos. Esa representación etnocéntrica se usa para «justificar» los sentimientos de superioridad que cada grupo alimenta en sus comparaciones con otros colectivos.

D. J. Levinson lo describe con estas palabras:

«El etnocentrismo se basa en una distinción siempre presente y rígida entre endogrupo y exogrupo; entraña imágenes negativas estereotipadas y actitudes hostiles con respecto a los exogrupos, imágenes positivas estereotipadas y actitudes de sumisión respecto a los endogrupos, y la idea de que la relación entre grupos debe ajustarse a niveles de jerarquía y autoridad en los cuales los endogrupos dominan por derecho propio y los exogrupos están en posición subordinada»

Levinson, D.J. En AdORNO et al. (1965). Pág. 159.

Tanto las narraciones de los libros de texto como las que ofrecen a los niños sus padres, amigos, profesores, medios de comunicación de masas, etc. pueden girar en torno a la separación entre «lo del grupo propio» y «lo de grupos ajenos».

Los ámbitos a los que puede estar aplicada la separación son muy variados. Ejemplos: la familia propia // otras familias; la ciudad propia // otras ciudades; el color de piel propio // otros colores de piel. Estas separaciones originan en los niños simpatías o antipatías que anteceden a la comprensión de los conceptos «familia», «ciudad», «color de piel», etc.

Tajfel advierte acerca de la temprana cristalización en los niños del etnocentrismo basado en la separación nacional:

«El etnocentrismo en los niños conforme se expresa en sus preferencias por los connacionales frente a los extranjeros cristaliza muy pronto en la vida, mucho antes que el concepto de nación (que a menudo presenta serias dificultades de definición, no sólo para los ciudadanos «corrientes", sino también para los historiadores y politólogos)»

TAJFEL, H. (1984). Pág. 195.

Anteriormente se ha expuesto que el estereotipo está cumpliendo, entre otras, una función de racionalización del prejuicio. Consecuentemente, un estereotipo desfavorable de un grupo sería la «justificación» de un prejuicio negativo respecto de ese mismo grupo.

El etnocentrismo (tal como ha sido definido por Levinson) estaría en la base, tanto de las actitudes prejuiciosas como de su justificación, el estereotipo. El modelo explicativo de Levinson es el siguiente:

\begin{tabular}{|llll}
\hline $\begin{array}{l}\text { - la distinción etnocéntrica: } \\
\text { lleva consigo la correspondiente }\end{array}$ & endogrupo & $\|$ & exogrupo \\
- distinción prejuiciosa: & $\begin{array}{l}\text { actitudes } \\
\text { de sumisión } \\
\text { (respecto }\end{array}$ & $\begin{array}{l}\text { actitudes } \\
\text { hostiles } \\
\text { (respecto }\end{array}$ \\
y la correspondiente & a los endogrupos) & a los exogrupos) \\
- distinción estereotípica: & imágenes// & imágenes \\
& $\begin{array}{l}\text { positivas } \\
\text { (de los endogrupos) }\end{array}$ & negativas \\
& (de los exogrupos)
\end{tabular}


Este modelo aparece como aceptado en una gran parte de los trabajos que se ocupan del tema en Psicología Social. La mayoría de los especialistas en el estudio de la estereotipia se muestran de acuerdo en que los endoestereotipos son expresados en términos favorables mientras que los exoestereotipos tienden a ser expresados en términos desfavorables: «las imágenes de los extranjeros son siempre parcialmente negativas" (Pool y Prasad, 1958, p. 293).

Algunos autores ${ }^{9}$ han señalado que los fenómenos «etnocentrismo» y «estereotipia» no van necesariamente unidos. Pero los resultados de la mayor parte de las investigaciones confirman que «los sujetos discriminan a favor del endogrupo y en contra del exogrupo y muestran actitudes más positivas hacia el primero que hacia el segundo» ${ }^{10}$. La repetida confirmación de tal hipótesis ha dado lugar al consenso en torno al «sesgo endogrupal» 0 «favoritismo endogrupal» ${ }^{11}$.

El análisis de los manuales puede abundar en la confirmación antedicha, pero también cabe la posibilidad de que, en alguno de los libros seleccionados, se elabore el relato de modo que el colectivo de personajes nacionales reciba peor tratamiento que otro/s colectivo/s. Ello llevaría a concluir que los sesgos no son siempre favorables al endogrupo.

Por otra parte, en aquellos casos en que se produzcan favoritismos endogrupales, nuestra tarea consistiría en examinar si tienen lugar en beneficio de todos los personajes nacionales o sólo de algunos colectivos, dentro del conjunto nacional. Dicho examen se llevaría a cabo comprobando si la distinción entre los personajes que reciben tratamiento favorable y los que reciben tratamiento desfavorable se establece en los textos siguiendo:

- sólo el criterio de nacionalidad,

- un criterio diferente de la nacionalidad, o

- una confluencia de criterios.

Este análisis permitiría aportar los matices que se consideren necesarios a la tesis del favoritismo endogrupal.

\section{Etnocentrismo, prejuicios y estereotipos en los libros de historia}

Los fenómenos denominados «estereotipia», «etnocentrismo» y "prejuicio» han sido detectados en los libros de historia por numerosos autores. Como ilustración, citamos los siguientes:

Young, al explicar la función de las leyendas, considera que el adiestramiento de cada nueva generación de niños en la historia de la sociedad a la que pertenece «es una etapa natural de nuestro etnocentrismo» (Young, 1974).

Julio Caro Baroja ha señalado en "Los pueblos de España»:

«Al estudiar la Etnología y la Historia antigua de Europa Occidental, se nota la falta de libros que traten de ellas dentro de un amplio terreno de especulación desinteresada. Un sin fin de prejuicios empobrecen la visión ofrecida: prejuicios de todas clases y fundamentalmente locales. La antipatía o simpatía que por razón de nacimiento se tiene a esto o aquello, se proyecta al pasado. Con constancia buscamos los rasgos de que nos enorgullecemos en nuestros ascendientes posibles o supuestos».

CARo Baroja, J. (1981). Pág. 12.

Dominique Perrot y Roy Preiswerk (1979) se propusieron en «Etnocentrismoe Historia» "ofrecer una decripción de la visión que los occidentales se han formado de sí mismos y del mundo a través de los últimos siglos». Describen los juicios de valor explícitos en los textos referidos a determinadas culturas. En los textos han encontrado una serie de manifestaciones del etnocentrismo «occidental» que se explicitan en el significado con el cual se usan las nociones "civilización», «evolucionismo social", 
«atraso cultural», etc. Todas estas manifestaciones de etnocentrismo están ilustradas con citas de los textos estudiados.

Las representaciones prejuiciosas y etnocéntricas están presentes en todas las culturas: aún cuando los manuales se presenten como "Historia mundial» o "universal», en cada país se eligen determinados capítulos de la Historia de otro/s país/es porque tienen más interés para las instituciones que controlan la producción de esos manuales. Por ejemplo, en los libros de Cuba ocupan un lugar preferente las referencias a las revoluciones mexicana y nicaragüense, además de la cubana.

\section{La ambigiiedad del concepto "nación»}

En los epígrafes anteriores se han descrito dos de los factores que hacen posible la formación de estereotipos nacionales en los libros de texto de Historia: la vicariedad de los textos de Historia y las tendencias prejuiciosas y etnocéntricas de los autores de los manuales. La ambigüedad del concepto de «nación» es el tercer factor que destacamos, de entre los que favorecen la formación de estereotipos en esta clase de relatos.

Aquello que tiene una naturaleza precisa se define describiendo los elementos que lo componen, desde un punto de vista determinado. Una vez elegido el criterio para su descripción, no es posible designarlo de forma estereotipada o simplificada, omitiendo alguno de sus elementos, puesto que ello supondría no designarlo. En cambio, sí puede ser estereotipado - de distintas maneras- lo que admite diferentes definiciones, bien porque en cada definición se incluye una parte de los elementos (pero no la totalidad), bien porque se incluyen componentes dispares (es decir, no adecuados a un solo criterio).

La definiciones de «nación» temiten tanto a bases materiales, como administrativas, lingüísticas, históricas, religiosas, axiológicas, etc. Según José Ramón Recalde, «los ingredientes esenciales que más predicamento han tenido han sido la religión, la raza, la lengua y una especie de sedimento cultural histórico que sería el espíritu de pueblo» ${ }^{12}$.

La posibilidad de describir a una nación con una serie de componentes dispares (por ejemplo: el «catolicismo", el "color blanco de piel», el "patriotismo», el «individualismo», etc.) permite un número indefinido de combinaciones de elementos. $\mathrm{Y}$, por tanto, innumerables representaciones estereotipadas o simplificadas de una misma «nación».

El análisis de los textos de Historia permitiría encontrar el conjunto de elementos (cualidades, sentimientos, relaciones entre actores, etc.) que los mediadores han estimado «adecuados» para construir las «señas de identidad nacional» en los países donde se utilizan los libros que sean objeto de análisis.

\section{PLANTEAMIENTO METODOLOGICO PARA EL ANALISIS DE LAS REPRESENTACIONES TRANSMITIDAS EN LOS TEXTOS}

\section{Definición del «análisis de contenido» o «análisis de representaciones»}

Se entiende por análisis de contenido «un conjunto de técnicas aptas para la exploración científica de materiales informativos: documentos, textos, periódicos, emisiones de radio o televisión, etc. ${ }^{13}$. En este caso, se utilizarían técnicas destinadas a inferir contenidos latentes de contenidos manifiestos. En otros casos, se utilizan técnicas destinadas a facilitar la documentación: índices, resúmenes, codificación, almacenamiento, etc.

El término «contenido» es más confuso que el término «representaciones». Con expresiones como «contenido de la comunicación» o «contenido del relato», 
según los autores, a veces se quiere designar datos de referencia o de evaluación y a veces se quiere designar objetos de referencia. Preferimos el término «análisis de representaciones», entendiendo por representación «la organización de un conjunto de datos de referencia en un modelo que posee algún sentido para el usuario o los usuarios de esa representación ${ }^{14}$.

David Berlo definía el contenido como «el material del mensaje que fuera seleccionado por la fuente para expresar su propósito (...) Cada afirmación puede ser considerada como elemento de contenido" (Berlo, 1976). Utilizando la terminología plasmada anteriormente, diremos que en el análisis de los manuales de Historia sería considerado como elemento de contenido «cualquier dato de referencia que pueda formar parte de un conjunto de datos organizado en un modelo de representación».

La complementariedad de los análisis cuantitativos y cualitativos. El análisis de las relaciones lógicas

El objeto de este epígrafe es explicar por qué se elige un método lógico para hacer el análisis de contenido, el cual ha de reunir inicialmente unas condiciones señaladas por Berelson (1952) la objetividad, la sistematización, el apoyo exclusivo sobre el contenido manifiesto y la cuantificación.

El requisito de la cuantificación ha suscitado muchas objeciones porque el cálculo de frecuencias se convirtió durante mucho tiempo en la actividad principal, y a veces única, de los analistas. Los elementos de un producto comunicativo, en numerosas ocasiones, se aislaban, se extraían de su contexto y se contabilizaban sin más.

Las técnicas de análisis que se utilicen en investigación de narraciones deben ser adecuadas para estudiar una actividad mediadora. Esto es, una «actividad que impone límites a lo que puede ser dicho y a las maneras de decirlo, por medio de un sistema de orden»(Martín Serrano, 1977).

Cabe aceptar (en tanto que la investigación no demuestre lo contrario) que las limitaciones o constricciones formales en el código empleado en una práctica comunicativa institucional suelen ser congruentes con las limitaciones o constricciones sociales: Por ejemplo, se ha podido llegar a mostrar recurriendo al análisis de las narraciones que unos prejucios compartidos en el seno de una comunidad se reflejan en las relaciones lógicas (inclusión, implicación, exclusión, etc.) que mantienen entre sí los datos de referencia contenidos en las narraciones.

El análisis de las relaciones lógicas es un instrumento con el cual puede objetivarse la estructura de los modelos comunicativos, donde se expresan cada una de las visiones del mundo propuestas por los mediadores culturales. Ello es posible con esta metodología porque son códigos lógicos los que se emplean en la comunicación para ejercer el control cognoscitivo. Otras instituciones, no especializadas en la producción de comunicación, ejercen el control sobre el conocimiento sirviéndose de códigos sociales (autorizaciones, prohibiciones, etc.).

En los análisis de estructuras narrativas, los resultados no se obtienen con los datos estadísticos que presentan las tablas de cruce, sino con la traducción de dichos datos a signos indicativos de las relaciones lógicas existentes entre las categorías de las variables que se cruzan. Con este fin, se distinguen cuatro clases de

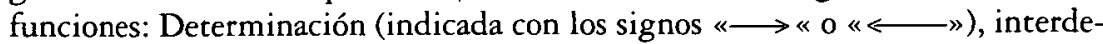

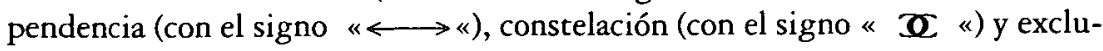
sión.(con el signo « $<\ll)^{15}$.

La figura 3 ofrece ejemplos de relaciones lógicas por las cuales se ha distinguido al endogrupo nacional de todos los restantes en libros de texto de Historia utilizados en cuatro países distintos en el año académico 1985/86. 
FIGURA 3

Ejemplos de relaciones lógicas por las cuales se distingue al endogrupo nacional de todos los restantes

\begin{tabular}{|lcl|}
\hline \multicolumn{3}{|c|}{ En los libros de CHILE } \\
La atribución de ciertos rasgos & $><$ & personajes \\
negativos asignados a los & (está & de \\
miembros de otros grupos & excluida & nacionalidad \\
(rasgos de inmoralidad) & para) & chilena \\
\hline
\end{tabular}

\begin{tabular}{|lcl|}
\hline & En los libros de PERU & \\
La atribución de ciertos rasgos & $><$ & personajes \\
negativos asignados a los & de \\
miembros de otros grupos & (está & nacionalidad \\
(rasgos indicativos de división & excluida & peruana \\
en clase sociales) & para) & \\
\hline
\end{tabular}

\begin{tabular}{|lll|}
\hline \multicolumn{2}{|c|}{ En los libros de CUBA } \\
La atribución de ciertos rasgos & $><$ \\
negativos asignados a los & (está & \\
miembros de otros grupos & excluida & \\
(indicativos de conflictos con & para) & $\begin{array}{l}\text { personajes } \\
\text { de } \\
\text { nacionalidad } \\
\text { La atribución de ciertos rasgos }\end{array}$ \\
$\begin{array}{l}\text { cubana } \\
\text { positivos no asignados a }\end{array}$ & & \\
los miembros de otros grupos & (está & \\
política) & determinada & \\
\hline
\end{tabular}

\begin{tabular}{|lll|}
\hline \multicolumn{3}{|c|}{ En los libros de ESPAÑA } \\
La atribución de ciertos rasgos & $><$ \\
negativos asignados a los & (está \\
miembros de otros grupos & excluida \\
(indicativos de atraso cultural & para) & \\
y absolutismo político) & & $\begin{array}{l}\text { personajes } \\
\text { de } \\
\text { nacionalidad } \\
\text { española }\end{array}$ \\
$\begin{array}{l}\text { La atribución de ciertos rasgos } \\
\text { positivos no asignados a }\end{array}$ & & \\
$\begin{array}{l}\text { los miembros de otros grupos } \\
\text { (indicativos de eficacia, }\end{array}$ & (está & \\
energía y moralidad) & determinada & por ser) \\
\hline
\end{tabular}

\section{Objetivos y procedimiento a seguir}

La explotación de los resultados ha de planificarse teniendo en cuenta el PAIS de los libros y la NACIONALIDAD de los actores si se quiere analizar la arquitectura que subyace en la representación de los grupos nacionales.

\section{Primer objetivo}

Un primer objetivo del análisis podría ser examinar el tratamiento que los libros de cada país dan a los distintos grupos de personajes (indígenas, iberoamericanos, españolẹs, etc.). Cabe esperar que las diferenciaciones más notables se establezcan entre las representaciones de los personajes que pertenecen al mismo país de los libros que se analizan y las representaciones de los actores pertenecientes a otros paises.

Con este fin, sería necesario describir el reparto de atributos empleados en los manuales de cada país, al caracterizar a personajes históricos de diferentes grupos 
nacionales. Para ello, se separarían las descripciones encontradas en los libros de cada país y se confeccionarían cuadros de doble entrada con la configuración siguiente:

Filtro: libros del PAIS «A» (p.e. Libros de Chile)

\begin{tabular}{|c|c|c|c|c|c|}
\hline \multirow[b]{2}{*}{ ATRIBUTOS } & \multicolumn{5}{|c|}{ NACIONALIDAD DE LOS PERSONAJES } \\
\hline & Indígena & Española & Europea & Chilena & Iberoamericana \\
\hline Humildad & $\longrightarrow$ & $><$ & $><$ & $>$ & $>$ \\
\hline Arrogancia & $<$ & $<-$ & $><$ & $><$ & \\
\hline $\begin{array}{l}\text { Inteligencia } \\
\ldots \ldots \ldots \ldots . . . \\
\ldots \ldots \ldots . . . \\
\ldots \ldots \ldots \ldots . .\end{array}$ & $><$ & $><$ & $><$ & $\longrightarrow$ & $>$ \\
\hline
\end{tabular}

Con tablas de este tipo, cabría describir:

a) Por una parte, las diferencias entre los rasgos atribuidos a los personajes del endogrupo y los atribuidos al conjunto de los personajes que no pertenecen al endogrupo. Por ejemplo: las diferencias entre la representación de los «chilenos» y la de todos los «no chilenos», en los libros de Chile.

b) Por otra parte, las diferencias entre los rasgos atribuidos a los personajes del endogrupo y los atribuidos a los de cada exogrupo, por separado. Por ejemplo: las diferencias entre la representación del endogrupo «chilenos» y la del exogrupo «españoles», en los libros de Chile.

\section{Segundo objetivo}

Un segundo objetivo del análisis podría consistir en glosar el perfil de cada grupo nacional, ofrecido en los libros de su propio país y en los de otros paises, con objeto de comprobar el grado de semejanza existente entre los manuales de distintos Estados al representar a personajes de una misma nacionalidad. A tal fin, es necesario analizar el contenido de los estereotipos de cada grupo nacional, en los libros de los diferentes países.

La configuración de estas nuevas tablas sería la siguiente (Se obtendría una tabla para cada NACIONALIDAD. Se adoptaría como variable independiente el PAIS al cual pertenecen los libros donde han aparecido las descripciones; y como variables dependientes los ATRIBUTOS asignados a los actores).

Filtro: actores de la NACIONALIDAD «X» (p.e. «MEXICANOS»)

\begin{tabular}{|l|c|c|c|c|c|}
\hline \multirow{2}{*}{ ATRIBUTOS } & \multicolumn{5}{|c|}{ PAIS DE LOS LIBROS } \\
\cline { 2 - 6 } Eficacia & Chile & Cuba & México & Perú & España \\
Energía & & & & & \\
$\ldots \ldots . . . . .$. & & & & & \\
$\ldots \ldots . . . . .$. & & & & & \\
\hline$\ldots . . . . .$. & & & & & \\
\hline
\end{tabular}

Con este nuevo tipo de tablas, cabría describir:

a) La representación estereotipada de los actores de una nacionalidad, ofrecida en los libros del mismo país al que pertenecen dichos actores. Por ejemplo, Rasgos que configuran el estereotipo de los mexicanos en los libros de México»; $y$ también

b) Las semejanzas y diferencias entre la representación de un grupo en los libros de su país y la representación del mismo grupo en los libros de otros países. Por ejemplo, «Comparación entre los rasgos atribuidos a los mexicanos en los libros de México y los atribuidos en los libros de otros países». 


\section{Tercer objetivo}

Las semejanzas y las diferencias entre las caracterizaciones de unos personajes y las de otros pueden estar relacionadas bien con su pertenencia a una u otra nación, bien con su inclusión en otra clase de agrupaciones (políticas, étnicas, etc.). La estructura de un estereotipo se pone de manifiesto cuando se descubren los filtros que han permitido la descripción de los personajes pertenecientes a los grupos «A»,


«3»...«n».

El tercero y más importante objetivo del análisis sería encontrar reglas de formación de estereotipos en la narración de los textos de Historia a partir de los resultados obtenidos en las explotaciones de datos mencionadas. Estos resultados están referidos tanto a la composición de cada estereotipo, como a las semejanzas y diferencias entre las representaciones de los distintos colectivos nacionales.

A fin de estudiar con qué criterios se construyen los estereotipos nacionales en los libros de Historia, se partiría del planteamiento siguiente: es posible que los autores de los textos seleccionen, consciente o inconscientemente, los datos que conforman la representación de los personajes, en función de la «nacionalidad» de éstos. $\mathrm{La}$ «nacionalidad» sería el primer criterio a tener en cuenta si se pretende explicar por qué la representación estereotipada de un grupo de personajes está construida con unos rasgos distintos a los que componen la de otro grupo.

Ahora bien, podría suceder que la pertenencia de los personajes a una u otra nacionalidad no fuese siempre el único elemento explicativo. Cabe la posibilidad de que las atribuciones con las cuales se describe a los personajes, se deriven de otros criterios diferentes (p.e.: la etnia, la posición política, etc.).

Este planteamiento permitiría verificar si hay libros de Historia en los que el contenido de las representaciones estereotipadas de los personajes pueda ser explicado solamente en razón de su nacionalidad y si existen otros libros, en los cuales la nacionalidad no sea el único o, tal vez, ni siquiera el principal factor explicativo de las diferentes caracterizaciones. Si se comprobaran las semejanzas y diferencias entre las representaciones del endogrupo y las de los exogrupos, también sería posible averiguar en qué casos esta funcionando cada uno de los criterios alternativos.

$\mathrm{El}$ interés de averiguar con qué criterio/s se construyen las representaciones grupales radica en lo siguiente: Los estereotipos "nacionales» pueden ser justificaciones de prejuicios «nacionales», pero también pueden estar justificando prejuicios de otro tipo, por ejemplo, étnicos o políticos. En los manuales de algunos países tal vez confluyan prejuicios de diferente naturaleza, al describir a determinados personajes, que estuviesen contemplados, al mismo tiempo, como miembros de un grupo nacional y como pertenecientes a un colectivo de otras características.

\section{QUE PUEDE HACER EL PROFESOR CON LOS LIBROS DE TEXTO DE HISTORIA}

\section{El profesor como analista}

Sean cuales sean los criterios que se sigan para caracterizar positiva o negativamente a los personajes nacionales y extranjeros, los juicios de valor cargados de xenofobia o de desprecio no suelen aparecer explícitos en los textos, lo cual no es óbice para que esa valoración esté implícita en la estructura narrativa y sea igualmente eficaz como estímulo prejuicioso. Por este motivo, la objetivación de los estereotipos que se transmiten a través de todas las vías de socialización de los individuos es un paso necesario para evitar prejuicios y xenofobias. En el sistema educativo, dicha objetivación de estereotipos podrían llevarla a cabo los profesores si aprenden a reconocer la arquitectura de las representaciones etnocéntricas.

La metodología ofrecida en las páginas precedentes puede ser usada, y su potencia analítica puesta a prueba, por quienes se ven en la necesidad de seleccionar, 
y después usar en las clases, uno o más libros de texto, de entre aquellos que han sido autorizados por las autoridades educativas. Para ello se requiere un entrenamiento en las técnicas de análisis de contenido con énfasis en la obtención de estructuras narrativas, no explícitas en los propios relatos, pero observables deconstruyendo el relato y construyéndolo con un orden diferente del que tiene.

Los resultadós del análisis permitirían a los profesores llevar a cabo su participación en el proceso de enseñanza - aprendizaje con un conocimiento más profundo de su principal herramienta de trabajo.

\section{El profesor como mediador}

El profesor - al igual que el libro- se convierte en un mediador entre los acontecimientos históricos y la visión que de ellos adquieren los estudiantes. A pesar de esa mediación y de otras que eventualmente pudieran concurrir -como las de los padres, p.e.- los libros de texto oficialmente autorizados son portadores de representaciones del mundo que gozan de legitimidad institucional.

La creencia de que el mundo es de una cierta manera puede persistir durante mucho tiempo en la mente de los sujetos. Si mediaciones como las antedichas (de los profesores, los padrés u otros agentes) son más bien lábiles o inexistentes, aquellas representaciones de las que el libro es portador serán las más persistentes en la conciencia de los individuos. Ante esta posibilidad, el profesor puede dar a conocer a los alumnos puntos de vista que no encontrarán en los manuales. P.e. con advertencias como las que siguen:

- Una narración puede estar orientada a dividir a la gente en blancos y negros, responsables e insensatos, amigos y enemigos, buenos y malos, etc. Las investigaciones y ensayos de los historiadores actuales ofrecen interpretaciones de los hechos históricos menos maniqueas que los historiadores de otras épocas y no tan simples como las presentadas por los libros de texto.

- El ámbito cuya historia nos concierne no es sólo el del Estado-nación porque además de ser miembros de una entidad de esa naturaleza, también lo somos de otros colectivos más o menos extensos geográficamente (nuestra ciudad, región, continente o planeta) y de grupos no delimitados por un territorio (p.e., profesionales, religiosos o étnicos), cuya historía puede ser tan interesante conocer como la historia del Estado-nación, máxime si en esta última no se refleja la diversidad de nuestras condiciones y experiencias vitales: las de hombres y mujeres; payos y gitanos; habitantes de ciudades grandes, pequeñas o núcleos rurales; banqueros, empleados, obreros, campesinos, aristócratas, etc. Aún cuando se trate de contar la historia de un país, ésta no debiera confundirse con la historia política; consecuentemente, los gobernantes, o el más amplio grupo de los políticos, no debieran tener en exclusiva el protagonismo en la historia de las naciones.

- No sólo existe una evaluación de ciertos grupos de personajes cuando se le adjudican rasgos negativos o adjetivos peyorativos, sino también cada vez que se llevan a cabo sesgos que ocultan o distorsionan una parte de la información referida a tales grupos y, por tanto, presentándoles de forma inapropiada.

- No existen países, razas, religiones o civilizaciones superiores o inferiores a otras, tanto si aparecieran así explícitamente como si se sugiere, introduciendo los criterios por los cuales se deducirían tales evaluaciones. El profesor debe advertir que existen otros criterios alternativos o complementarios, que, de ser incluídos en el relato, permitirían obtener una representación menos sesgada de los diferentes actores.

En resumen, la participación del profesor, debe tener presente lo que sigue: es muy importante examinar lo que se enseña como Historia en las escuelas porque nuestra percepción del presente (lo que creemos ser o no ser, en relación a otros) se construye, entre otros elementos, por la manera en la que entendemos que ha transcurrido el pasado. Ahora bien, el modo en que se cuenta la Historia es uno entre otros posibles. 
planificado para socializarnos, dándonos una visión de «nuestra» comunidad y de "otras" comunidades, y sugiriendo o expresando abiertamente cual es "nuestra" posición en el mundo. Ese «nos-otros» es susceptible de ser delimitado con infinidad de criterios y puntos de vista.

A este respecto, conviene que la enculturización de los niños y adolescentes (como de los adultos) les capacite para estar siempre dispuestos a conocer a los demás habitantes del planeta sin distorsiones y prejuicios etnocéntricos. En materia de Historia, el conocimiento de los diversos pueblos, culturas o grupos sociales, debe hacerse incorporando interpretaciones del acontecer de procedencias distintas.

\section{Notas}

1 El antropólogo Marvin Harris, tras atribuir a la enculturización un papel en el mantenimiento de las pautas de conducta y de pensamiento de cada grupo, afirma que la incomprensión de este papel forma el núcleo del fenómeno que llamamos etnocentrismo. Harris, M. 1982. pág. 125.

2 Se atribuye a Durkheim la utilización, por primera vez, del término «representaciones colectivas", abriendo con ello la posibilidad de considerarlas como objeto de estudio autónomo.

3 Los manuales de Historia no son los únicos que intervienen en la formación de una imagen del grupo propio y de los ajenos. Los textos de literatura, idiomas, geografía, entre otros, también tienen su efecto en las representaciones del mundo que se forman los alumnos. Otros relatos, no considerados hoy como libros de texto, sino de creación literaria (p.e. «La Iliada»), han desempeñado en su día una función semejante.

4 Las reflexiones sobre la naturaleza o el carácter de los pueblos parecen abundar más después de determinados acontecimientos históricos: En México, después de su revolución; en España, a raíz de la pérdida de Cuba: en Argentina, la guerra de las Malvinas es uno de los últimos episodios que hace recapacitar a sus ciudadanos sobre «lo que son».

5 Respecto a la relación entre carácter e historia de un pueblo, O. Paz opina lo siguiente:

«Las circunstancias históricas explican nuestro carácter en la medida que nuestro carácter también las explica a ellas. Ambas son lo mismo. Por eso toda explicación puramente histórica es insuficiente - lo que no equivale a decir que sea falsam. Paz, O. 1986. Pág. 65.

6 El cambio histórico en la naturaleza de los datos de referencia de la comunicación, en Martín Serrano et al. 1981. Pág. 182.

7 «Los datos de referencia, desde la perspectiva de la comunicación, son un conjunto de expresiones asociadas a un conjunto de representaciones». Martín Serrano et al, 1981. Pág. 147-148.

8 Pool y Prasad, 1958, p. 293 citado en Sangrador, J.L. 1981. Pág. 99.

9 «Karlins, Coffman y Walter insisten en esta idea, al afirmar que «el etnocentrismo, evidentemente, no es inherente a la estereotipia, en sí misma» (1969. Pág. 12)». Citado en Sangrador, J.L. 1981. Pág. 99.

10 Morales Domínguez, J.F. «Identidad social y personal ». En Rodríguez, A., y Seoane, J. 1989. Pág. 59.

11 «El apoyo experimental con que cuenta la tendencia al favoritismo endogrupal se refiere a diferentes aspectos de la misma. Se ha encontrado que se atribuye a los miembros del endogrupo las características físicas más deseables (Doise et al., 1972), así como las creencias más parecidas a las suyas (Allen, Wilder, 1975). Además, se tiende a evaluar más positivamente las tareas realizadas por el endogrupo (Hinkle y Shopler, 1979), a asignar ítems más positivos a sus miembros (Howard y Rothbart, 1978) y a otorgarles los valores estimados más deseables (Locksley et al., 1980), todo ello en comparación con el exogrupo». Munne, F. «Prejuicios, estereotipos y grupos sociales». En Rodríguez, A., y Seoane, J. 1989. Pág. 345.

12 Recalde, J.R. El País, 2-6-88. Suplemento Temas de nuestra época. Pág. 6.

13 Piñuel, J.L.: «Análisis de contenido» en Martín Serrano y otros 1978 b). Pág. 1.

14 Martín Serrano, M.: Los modelos de la comunicación ( $3 .^{a}$ parte): propuesta de un modelo dialéctico para el estudio de los sistemas de comunicación, en Martín Serrano, et al. 1981. Pág. 147-148.

15 En «L'ordre du monde à travers la Tv.» (Martín Serrano, M. 1976) se investigó por primera vez el sistema de formación de estereotipos en la televisión, sirviéndose de las mismas funciones lógicas que utilizariamos para estudiar la formación de estereotipos en los libros de texto de Historia.

16 Por ejemplo, las interpretaciones no europeas de la Historia servirían para entender que la acción europea en el mundo, o la transferencia de valores europeos a sociedades no europeas, no tienen por qué ser legitimadas en todas partes.

\section{Referencias}

AdORNO, T.W. et al. (1965): La personalidad autoritaria. Buenos Aires. Proyección

AџPORT, G. W. (1971): La naturaleza del prejuicio. Buenos Aires. Eudeba.

BERLO, D. K. (1976): El proceso de la comunicación. -Introductión a la teoría y a la práctica-. Buenos Aires. Librería «El Ateneo».

Berelson, B. (1952): Content Analysis in Communications Reserch. Glencoe. The Free Press.

BILuNG, M. (1984) «Racisme, préjuré et discriminación». En MOSCOVICI, S. (dir.). Psycbologie sociale. París, P.U.F. 
CARO, J. (1985). Las Pueblos de España. Madrid: ISTMO.

Garmendia, J. A.; Parra luna, F. y Perez, A.(1982):. A bertzales y vascos. Madrid: Akal.

HARRIS, M. (1982): Introducción a la antropología general. Madrid. Alianza.

HERNANDEZ, F. y MERCADE, F. (1986): Estructuras sociales y cuestión nacional en España. Barcelona. Ariel. HJELMSLFV (1978): Prolégomènes à une théorie du langage. París: Minuit.

HorkHeimer, M. (1972): «Sobre el prejuicio». Frakfurter Allgemeine Zeitung. 20 Mayo 1961. En: Sociedad en transición: estudios de filosofa actual. Barcelona. Planeta-Agostini

MARTIN BARBERO, J.: «Identidad, comunicación y modernidad en América Latina». 16 Congreso Internacional de AIERI. Barcelona. Julio - 1988.

MARTIN SERRANO, M. (1974): «Nuevos métodos para la investigación de la estructura y la dinámica de la enculturización». Revista Española de la Opinión Pública, 37. 23-83.

MARTIN SERRANO, M. (1976): L'ordre du monde à travers la tv. -Structure du discours electronique. Thèse de Doctorat d'Etat. Univ. L. Pasteur. Strasbourg. Lille. Presses Universitaires.

MARTIN SERrano, M. (1977): La Mediación Social. Madrid. Akal.

MARTIN SERRANO, M. (1978 a): “Un método lógico para analizar el significado». R.E.I.S. 2. ,21-52.

Martin Serrano, M. et al (1978 b): «Métodos de análisis de contenido». Madrid, Departamento de Comunicación.

MARTIN SERRANO, M. et al (1981): Teoría de la Comunicación: Epistemología y análisis de la referencia. Madrid. A.C. editor.

MARTIN SeRrANO, M. (1986): La producción sacial de comunicación. Madrid. Alianza

Moscovici, S. (1986).: Psicología social (I, II). Barcelona. Paidós.

PAZ, O.(1986): El laberinto de la soledad. Madrid. Fondo de Cultura Económica.

Perrot, D., y PreIsWERK, R. (1979). Etnocentrismo e Historia. -América indigena, Africa, Asia en la visión distorsionada de la cultura occidental-. México: Nueva Imagen.

RODRIGUEZ, A., y SEOANE, J. (1989): Creencias, actitudes y valores. Madrid. Alhambra.

SANGRADOR, J.L. (1981): Estereotipos de las nacionalidades y regiones de España. «Monografías» 40. Madrid. Centro de Investigaciones Sociológicas.

TAJFEL, H. (1984): Grupos bumanos y categorías sociales. Estudio de psicología social. Barcelona. Herder.

Young, K. (1974): Psicología social. Versión castellana de Eliseo Verón. Buenos Aires:Paidos.

\section{Cómo analizar las representaciones sociales contenidas en los libros de texto de Historia Francisco Bernete$$
\text { CL\&E, 1994, 22, pp. 59-74 }
$$

Resumen: Desde las pintadas xenófobas hasta las llamadas "limpiezas étnicas" por las armas, pueden registrarse muy diversos indicadores de prejuicios manifiestos y latentes. Este artículo se presenta con el objeto de mostrar que es posible objetivar los contenidos latentes de determinados productos culturales, a partir de los datos explícitos. Con tal propósito, se ofrece una metodología específica para analizar las representaciones de grupos nacionales contenidas en libros de texto de Historia, contemplados en cuanto productos comunicativos que intervienen en la enculturización de los estudiantes y que, como tales, pueden ser fuente de prejuicios.

Datos sobre el autor: Francisco Bernete es profesor de Teoría de la Comunicación, en la Faculrad de Ciencias de la Información de la Universidad Complutense de Madrid.

Dirección: Departamento «Sociología IV (Sección de Comunicación); Facultad de Ciencias de la Información. Ciudad Universitaria. 28040 Madrid.

(C) PERMISOS PARA CITAR O REPRODUCIR EN OTRAS FUENTES: Se pueden citar libremente hasta 500 palabras. Para reproducir una porción de texto mayor, figuras o ilustraciones, se deberá pedir permiso por escrito a la revista, especificando el uso al que se destina el texto. En todos los casos, se deberá citar el copyright de $C L \& E$. En el caso de artículos o textos que hayan sido a su vez reproducidos en $C L \& E$ los interesados deberán dirigirse tanto a los detentadores del copyright original como a $C L \& E$, en el caso de que se quiera hacer uso de la traducción. FOTOCOPIAS: Para todo lo relacionado con el uso mediante fotocopia del material de esta revista, deberán dirigirse a: CEDRO, C/ José Marañón, 10,3. ${ }^{\circ}$ Izda. Tel. 5941575 . Fax 4453567 